\title{
Optical and structural properties of $\mathrm{Nb}_{2} \mathrm{O}_{5}-\mathrm{SiO}_{2}$ mixtures in thin films
}

Vesna Janicki $^{\mathrm{a}^{*}}$, Jordi Sancho-Parramon ${ }^{\mathrm{a}}$, Sergiy Yulin ${ }^{\mathrm{b}}$, Marcel Flemming ${ }^{\mathrm{b}}$, Andrey Chuvilin $^{\mathrm{c} 1}$

${ }^{a}$ Ruđer Bošković Institute, Bijenička c. 54, 10000 Zagreb, Croatia

${ }^{b}$ Fraunhofer-Institut für Angewandte Optik und Feinmechanik IOF, Albert-Einstein Str. 7, 07745 Jena, Germany

${ }^{c}$ University of Ulm, Albert Einstein Allee 11, 89069 Ulm, Germany, ${ }^{1}$ Present address: CIC nanoGUNE Consolider, Av. de Tolosa 76, 20018, San Sebastian, Spain and IKERBASQUE, Basque Foundation for Science, 48011, Bilbao, Spain

*Corresponding author: janicki@irb.hr, tel. + 3851 4571247, fax + 38514680108

\begin{abstract}
Mixture material thin films are used in gradient index optical systems due to their tailorable refractive index. To be able to realize the required optical performance of the system it is necessary to relate refractive index profile of the design to the volume fraction of components of the mixture. In this study it is reported that for electron beam co-deposited $\mathrm{Nb}_{2} \mathrm{O}_{5}-\mathrm{SiO}_{2}$ mixtures the most appropriate effective medium theory is Lorentz-Lorenz theory. Optical properties of a mixture are related to the structure of the composite. The structural properties of the studied mixtures justify the appropriateness of application of Lorentz-Lorenz theory to this kind of effective medium.
\end{abstract}

Keywords: optical characterization, optical properties, structural properties, material mixture, effective medium theory 


\section{Introduction}

Optical thin film coatings having refractive index that is continuously changing as a function of depth of the layer are known as gradient index films or inhomogeneous films. Gradient index systems may provide advantages in optical performance and mechanical properties in comparison to conventional HL-stack designs with alternating layers of materials of high and low refractive index. Excellent theoretical work on optical behaviour of gradient index films has been published during the last decades [1-3]. Additional profits that can be expected from inhomogeneous coatings are low stress, tribological resistance [4-6] and higher laser induced damage threshold [7] than classical multilayer stacks.

In order to obtain desired design and optical performance it is necessary to calculate the optical constants of the material mixture that is used in the design and later deposited. The optical constants can be calculated using different mixing models. These models relate the optical constants of the mixture of given composition with the optical constants of the pure materials. Several models, known as effective medium theories, have been proposed: Bruggeman [8], Lorentz-Lorenz [9], Maxwell Garnett [10] or a linear combination of refractive indices [11]. Effective medium theories (EMTs) appropriate to the material mixture deposited by the given technique should be applied for optical characterisation, as well as for design.

In this study, the appropriateness of Lorentz-Lorenz model for calculation of refractive index of $\mathrm{Nb}_{2} \mathrm{O}_{5}-\mathrm{SiO}_{2}$ mixtures in optical characterisation, and therefore the necessity to introduce it into design software [11, 12], was tested. Mixture samples of constant refractive index through the layer, with different concentration of $\mathrm{SiO}_{2}$ to $\mathrm{Nb}_{2} \mathrm{O}_{5}$, were deposited in order to check experimentally the EMT that best describes $\mathrm{Nb}_{2} \mathrm{O}_{5}-\mathrm{SiO}_{2}$ mixtures.

Appropriateness of Lorentz-Lorenz model was related to the structure of the mixtures by additional measurements: FTIR (Fourier Transform Infrared), TEM (transmission electron microscopy), XRD (X-ray Diffraction) and AFM (Atomic Force Microscopy). In order to verify the correlation of the structure with the result of optical characterisation, samples were annealed. It can be expected that upon thermal treatment phases will be separated and the optical properties will follow Bruggeman or Maxwell Garnett law, which are more appropriate for this kind of mixtures.

\section{Theory}

In this section is given an overview of material properties necessary to understand the experimental results found in this work. Also, a brief description of EMTs is given to explain their suitability to the studied mixtures. 


\subsection{Materials}

$\mathrm{SiO}_{2}$ films are amorphous, having compressive stress. Crystallisation occurs upon thermal treatment at temperatures above $1100^{\circ} \mathrm{C}$. The characteristic bonds of fused silica detectable by infrared spectroscopy are at [13] $1220 \mathrm{~cm}^{-1}, 1080 \mathrm{~cm}^{-1}, 800 \mathrm{~cm}^{-1}$ and $460 \mathrm{~cm}^{-1}$.

As deposited $\mathrm{Nb}_{2} \mathrm{O}_{5}$ films are mainly amorphous and do not crystallize easily. Coatings are wear resistant and fairly hard. For pure $\mathrm{Nb}_{2} \mathrm{O}_{5}$ onset of crystallisation is between $400^{\circ} \mathrm{C}$ and $500^{\circ} \mathrm{C}$ [14-16] resulting in hexagonal structure (Powder Diffraction File [17]: card No. 28-0317) while at temperature between $600^{\circ} \mathrm{C}$ and $700^{\circ} \mathrm{C}$ orthorhombic structure (Powder Diffraction File [17]: card No. 30-0873 or 27-1003) appears [16]. Characteristic feature of pure $\mathrm{Nb}_{2} \mathrm{O}_{5}$ infrared spectra is absorption band around $600 \mathrm{~cm}^{-1}$ corresponding to $\mathrm{Nb}-\mathrm{O}$ bonds of slightly distorted $\mathrm{NbO}_{6}$ octahedra [16]. This band increases with increase of temperature, splits and shifts to lower frequency, suggesting the existence of different $\mathrm{Nb}-\mathrm{O}$ species or in equivalent $\mathrm{Nb}-\mathrm{O}$ groups. Band at $850 \mathrm{~cm}^{-1}$ corresponds to $\mathrm{Nb}-\mathrm{O}-\mathrm{Nb}$ stretching [18].

There are studies reporting that $\mathrm{SiO}_{2}$ stabilizes amorphous $\mathrm{Nb}_{2} \mathrm{O}_{5}$ [19]. It is known that $\mathrm{Nb}_{2} \mathrm{O}_{5}$ crystallisation can be different according to the interactions between the compounds. Considering this fact, the structure of pure $\mathrm{Nb}_{2} \mathrm{O}_{5}$ is very different than when it makes a system with other species. The interaction between $\mathrm{Nb}_{2} \mathrm{O}_{5}$ and other materials affects its stability and, consequently, the final structure. When a strong interaction is established via Si$\mathrm{O}-\mathrm{Nb}$ linkages, the superficial $\mathrm{Nb}_{2} \mathrm{O}_{5}$ presents only the amorphous phase after thermal treatment at $500^{\circ} \mathrm{C}$ for 2 hours [19]. Even after 48 hours of treatment at $1000^{\circ} \mathrm{C}$ only weak diffraction peaks were attributed to the hexagonal phase. The interactions between $\mathrm{Nb}_{2} \mathrm{O}_{5}$ and $\mathrm{SiO}_{2}$ are responsible for $\mathrm{Nb}_{2} \mathrm{O}_{5}$ stabilisation, as they reduce $\mathrm{Nb}_{2} \mathrm{O}_{5}$ mobility thus preventing crystallisation. It is shown that a strong interaction between $\mathrm{SiO}_{2}$ and $\mathrm{Nb}_{2} \mathrm{O}_{5}$ is established during the sol-gel process, i.e. it involves the formation of Si-O-Nb bonds [19]. This conclusion was made based on the observation of infrared band between $930 \mathrm{~cm}^{-1}$ and 920 $\mathrm{cm}^{-1}$ that disappears with agglomeration process after high temperature treatment.

\subsection{Effective medium theories}

Typically, when considering material mixtures, it is assumed that the composing materials are present in the mixture as phases of microstructure that are big enough to maintain the same optical properties as in a layer of a single material, but small in comparison to the wavelength of the incidence light. In this way the medium is microscopically heterogeneous, but macroscopically homogeneous. To fulfil this condition for the visible and up to mid-infrared wavelengths, the microstructure should have dimensions typically 3-30 nm [20] (the shorter the wavelength, the lower the upper limit of the size). 
EMTs are developed for description of properties of such effectively homogeneous media [21]. The most widely used are Maxwell-Garnett [10] (MG), Bruggeman [8] (BG) and Lorentz-Lorenz [9] (LL) effective medium theory. The equations for two-material mixtures look as follows (Equation 1-4.):

$$
\begin{array}{ll}
\text { MG } & \frac{\varepsilon_{\text {eff }}-\varepsilon_{H}}{\varepsilon_{e f f}+2 \varepsilon_{H}}=\left(1-f_{H}\right) \frac{\varepsilon_{L}-\varepsilon_{H}}{\varepsilon_{L}+2 \varepsilon_{H}} \\
\mathrm{BG} & f_{H} \frac{\varepsilon_{H}-\varepsilon_{\text {eff }}}{\varepsilon_{H}+2 \varepsilon_{e f f}}+\left(1-f_{H}\right) \frac{\varepsilon_{\mathrm{L}}-\varepsilon_{\text {eff }}}{\varepsilon_{L}+2 \varepsilon_{\text {eff }}}=0 \\
\mathrm{LL} & \frac{\varepsilon_{\text {eff }}-1}{\varepsilon_{\text {eff }}+2}=f_{H} \frac{\varepsilon_{H}-1}{\varepsilon_{H}+2}+\left(1-f_{H}\right) \frac{\varepsilon_{L}-1}{\varepsilon_{L}+2} \\
\mathrm{LIN} & \sqrt{\varepsilon_{\text {eff }}}=f_{H} \sqrt{\varepsilon_{H}}+\left(1-f_{H}\right) \sqrt{\varepsilon_{L}}
\end{array}
$$

Here $\varepsilon_{e f f}, \varepsilon_{H}$ and $\varepsilon_{L}$ are the effective dielectric functions of the mixture, high and low index material, respectively. Volume fractions of high and low index material are $f_{H}$ and $f_{L}$, where $f_{H}+f_{L}=1$.

The first two theories assume that the mixing materials are in the separated phases. MG considers the mixture that has separated two (or more) grain structure where particles of the first material are dispersed in the continuous host of the second material. The host in Equation1 is high index material. On the other hand, BG assumes aggregate structure having a space filling random mixture of two (or more) material phases. In the limit of small volume fractions $\left(f_{v}\right)$ the predictions of the two theories approach to each other. It is shown that in the case of higher filling factors, i.e. when volume fraction of one material is comparable to the volume fraction of another, the BG is valid up to a smaller particle radius than MG [20]. LL takes an average of molecular polarizability of the components. In this case no phase separation is considered as it is supposed that the mixture is realized at atomic/molecular scale.

An additional simple model is the linear model (LIN) that considers linear dependence of refractive index on the volume fractions of the constituents [9].

\section{Experimental details}

\subsection{Deposition of samples}

A Leybold Syrus Pro 1100 deposition system is used successfully for electron beam co-evaporation of $\mathrm{Nb}_{2} \mathrm{O}_{5}-\mathrm{SiO}_{2}$ mixture coatings and gradient index films [22, 23]. The chamber is equipped with two electron beam guns, two crucibles with evaporation materials and plasma source. The deposition rates $(r(t))$ are measured by two quartz crystal monitors, 
one for each material. The concentrations of materials in the deposited layer, and therefore its refractive index, are controlled by emission current of electron beam gun. Deposition rate of each material is kept constant during fabrication of each sample.

The deposition of the materials $\left(\mathrm{Nb}_{2} \mathrm{O}_{5}\right.$ and $\left.\mathrm{SiO}_{2}\right)$ was performed in argon atmosphere as a working gas. Additionally, oxygen was employed as reactive gas to maintain the stoichiometry of the evaporated materials. Typical basic pressure before start of the deposition was $4 \times 10^{-7}$ mbar. Prior to the deposition the substrates were heated in the deposition chamber up to $150^{\circ} \mathrm{C}$, which was the working temperature. Substrates were cleaned first in ultrasound bath and additionally by plasma etching for 3 minutes in the deposition chamber. To insure uniformity of the film thickness across the substrate, the substrates were put to the calotte rotating with the speed of approximately $20 \mathrm{rpm}$. The material crucibles were set to rotation of $0.2 \mathrm{rpm}$ to prevent deformation of the vapour cloud due to decreased quantity of material in the crucible during long processes. In each deposition process Suprasil and silicon wafer chunk were used as substrates.

Mixture layers of constant composition through thickness, differing in ratio of $\mathrm{SiO}_{2}$ to $\mathrm{Nb}_{2} \mathrm{O}_{5}$ were deposited to verify which EMT is the best for characterisation of $\mathrm{Nb}_{2} \mathrm{O}_{5}-\mathrm{SiO}_{2}$ mixtures. For this purpose five coatings were manufactured with volume fraction of $\mathrm{SiO}_{2}$ $f_{v}\left(\mathrm{SiO}_{2}\right)$ ranging from approximately 0.2 to 0.8 in more or less equal steps. Deposition rates for the sample with maximum $\left(\mathrm{n}_{\mathrm{M}}\right)$, a bit lower than maximum $\left(\mathrm{n}_{\mathrm{M}-\mathrm{x}}\right)$, medium $\left(\mathrm{n}_{\mathrm{MED}}\right)$, a bit higher than minimum $\left(\mathrm{n}_{\mathrm{m}+\mathrm{x}}\right)$ and minimum $\left(\mathrm{n}_{\mathrm{m}}\right)$ content of $\mathrm{Nb}_{2} \mathrm{O}_{5}$ are shown in table 1 . In the same table are presented $f_{v}\left(\mathrm{SiO}_{2}\right)$ and expected thicknesses calculated from $r(t)$ recorded during the deposition. Deposition time for all the samples was $310 \mathrm{~s}$. The samples were postannealed for 5 hours in the air at $500^{\circ} \mathrm{C}$ and $750^{\circ} \mathrm{C}$.

\subsection{Measurements}

Spectrophotometric measurements of reflectance and transmittance at $6^{\circ}$ incidence in the range 350-950 $\mathrm{nm}$ were performed for optical characterisation of the deposited samples with a Perkin Elmer Lambda 900 spectrophotometer. A VN-attachment allowing absolute measurement of reflectance without moving the sample after the transmittance measurement was applied. For the optical characterisation of the samples, general-purpose software [24] (NKDMatl) was used. Fitting the experimental spectra the software allows determination of the optimal value of a set of parameters defining the sample. The layers were represented as coatings of unknown thickness $d$ and refractive index $n$, following either Tauc-Lorentz [25] or Cauchy [26] dispersion law. Fitting optical characteristics of the model to the experimental 
data gives values of optical parameters of the applied dispersion law and thickness of the layer.

FTIR measurements can detect absorption band related to the presence of Si-O-Nb bonds, indicating the level of mixing of the two phases. The peaks present the dependence of band intensity on concentration of the bonds and $\mathrm{Nb}_{2} \mathrm{O}_{5}$ and the annealing temperature. This band should decrease, while the one associated with Si-O-Si bonds should increase in intensity as a function of temperature. That indicates separation into phases. FTIR measurements were done by BIO-RAD FTIR spectrometer model FTS 175. The spectra were measured in the wavenumber range $400-7000 \mathrm{~cm}^{-1}$. XRD technique can also show the level of mixing of $\mathrm{SiO}_{2}$ and $\mathrm{Nb}_{2} \mathrm{O}_{5}$. If no diffraction peaks are detected it means that the mixture is amorphous or crystallites are very small (less than 2-3 nm) [27]. In this case the phases cannot be distinguished. Presence of diffraction peaks indicates crystallinity in the coating and separation of materials into phases. XRD was performed by Burker D505 diffractometer using $\mathrm{Cu}-\mathrm{K} \alpha$ radiation at $0.154 \mathrm{~nm}$, applying large angle $\mathrm{X}$-ray diffraction method. The samples deposited on Suprasil substrates were subjected to XRD analysis. The measurements were performed in the range of angles $7.5^{\circ}-30^{\circ}$. AFM was done to detect crystalline grains eventually formed on the layer surface after thermal treatment. The samples were measured at different scan sizes $(1 \mu \mathrm{m}$ X $1 \mu \mathrm{m}$ and $10 \mu \mathrm{m}$ X $10 \mu \mathrm{m})$. All the mentioned measurements were performed at IOF, Jena, Germany. Selected Area Electron Diffractions (SAED) obtained in TEM can confirm the level of crystallisation found by XRD. Conventional TEM, high resolution TEM (HRTEM) and Z-contrast STEM (HAADF STEM) images can illustrate structure of the layer in sense of distribution of materials and grains demonstrating again restructuring of the materials and separation into phases. TEM study was done at Titan 80300 TEM at the University of Ulm, Germany.

\section{Results}

\subsection{Optical characterisation}

The five mixture layers deposited on Suprasil were measured as deposited (AD) and after five hours of annealing in the air at $500^{\circ} \mathrm{C}$ and $750^{\circ} \mathrm{C}$. The sample with pure $\mathrm{Nb}_{2} \mathrm{O}_{5}$ layer was treated in the same way. The sample with pure $\mathrm{SiO}_{2}$ layer was not annealed since the structural changes in this material are expected only at higher temperatures. Upon annealing at $750^{\circ} \mathrm{C}, \mathrm{Nb}_{2} \mathrm{O}_{5}$ sample checked by naked eye showed milky reflection typical for high scattering indicating crystallisation in the layer. Therefore, optical characterisation could not have been performed. For this reason, scattering measurements were performed for $\mathrm{Nb}_{2} \mathrm{O}_{5}$ 
and other annealed high content $\mathrm{Nb}_{2} \mathrm{O}_{5}$ samples by Perkin Elmer Lambda 19 spectrometer with Ulbricht integrating sphere. No significant scattering (S) was detected at any of the samples annealed at $500^{\circ} \mathrm{C}$. Scattering spectra for samples annealed at $750^{\circ} \mathrm{C}$ are presented in figure 1. Peaks in spectra of $\mathrm{Nb}_{2} \mathrm{O}_{5}$ and $\mathrm{n}_{\mathrm{M}}$ samples (figure 1) correspond to peaks in reflectance spectra (not shown): the more light is reflected, the more light is scattered. There is no significant absorption in the range $350-950 \mathrm{~nm}$ for AD and 400-950 nm for annealed samples. The results of optical characterisation, using Tauc-Lorentz (TL) or Cauchy model (C) with exponential absorption, are shown in table 2. The samples showing scattering were rotated $90^{\circ}$ and their reflectance measured again. No anisotropy was found in this way. Optical characterization did not show significant inhomogeneities of refractive index through the thickness of the layers. The dispersions of the refractive indices are presented in figure 2.

\subsection{FTIR}

Before each FTIR measurement a spectrum of a reference $\mathrm{Si}$ substrate was taken as a background, so the data presented at figure 3 and figure 4 are solely spectra of the deposited layers. Figure 3 shows absorption curves of $\mathrm{AD}$ and annealed samples in the range where Si$\mathrm{O}-\mathrm{Si}, \mathrm{Nb}-\mathrm{O}$ and $\mathrm{Si}-\mathrm{O}-\mathrm{Nb}$ bands are expected. In figure 4 are FTIR spectra in the range where water absorption band is expected [28]. Absorbance $A$ is obtained from measurement of the sample and $A_{s u b}$ from measurement of the reference bare Si substrate. The measurements were taken 7 days after deposition, when no further water absorption was detected.

\section{3. $X R D$}

The small angle X-ray reflection (SAXR) and the large angle X-ray diffraction (LAXD) measurements were performed in Bragg-Brentano geometry $(\Theta-2 \Theta)$ using CuKa radiation $(\lambda$ $=0.154 \mathrm{~nm}$ ). The LAXD measurements are shown in figure 5. The peaks correspond to hexagonal and orthorhombic crystalline structure of $\mathrm{Nb}_{2} \mathrm{O}_{5}$. The values of root mean square (RMS) surface roughness obtained from these measurements, same as density of the samples, are presented in table 3 . Also, the density of the layers was determined from approximately $100 \mathrm{~nm}$ top thickness of the film.

\section{4. $A F M$}

The AFM topographs of $\mathrm{AD}$ and annealed $\mathrm{Nb}_{2} \mathrm{O}_{5}$ and $\mathrm{n}_{\mathrm{M}}$ layers deposited on Suprasil are shown in figure 6 and figure 7. The average roughness values obtained from several AFM measurements are given in table 3 and compared with values obtained from XRD. 


\subsection{TEM}

Selected area electron diffraction (SAED) and TEM images of $\mathrm{n}_{\mathrm{M}}$ sample, AD and annealed at $750^{\circ} \mathrm{C}$, deposited on $\mathrm{Si}$ are shown in figure 8 and figure 9, respectively. High angle annular dark field scanning TEM (HAADF STEM) image is presented as well. SAED patterns include crystalline reflections of Si substrate as internal calibration standard.

\section{Discussion}

Since the band gap for $\mathrm{SiO}_{2}$ and $\mathrm{Nb}_{2} \mathrm{O}_{5}$ is around $8 \mathrm{eV}(160 \mathrm{~nm})$ and $3.3 \mathrm{eV}(375 \mathrm{~nm})$, respectively, for optical characterisation in the spectral range of interest Cauchy model is appropriate for $\mathrm{SiO}_{2}$ and low content $\mathrm{Nb}_{2} \mathrm{O}_{5}$ samples. Tauc-Lorentz model is more appropriate for $\mathrm{Nb}_{2} \mathrm{O}_{5}$ and samples with high content of this material. As mentioned before, due to significant scattering of $\mathrm{Nb}_{2} \mathrm{O}_{5}$ sample annealed at $750^{\circ} \mathrm{C}$ (figure 1), optical characterisation of this sample could not be performed. However, due to low scattering for $n_{M}$ sample instead of Tauc-Lorentz, Cauchy model was applied. Cauchy model in combination with exponential absorption law, it simulates the effect of scattering more successfully than Tauc-Lorentz that is not able to account for optical losses below band-gap. For characterisation of this sample reflectance and transmittance measurements in the range $400-900 \mathrm{~nm}$ (where scattering is lower than $1 \%$ ) were used. The other samples did not present significant scattering.

The thicknesses obtained from optical characterisation (table 2) are higher than those calculated from deposition rates (table 1) possibly because of higher porosity, but also due to the changes in deposition conditions from one process to another. Indeed, comparing the differences of thicknesses calculated from $r(t)$ and those obtained from optical characterisation, it is possible to see that higher differences correspond to the AD samples with higher water content (see figure 4), that is related to porosity. The thickness reduces with annealing temperature: around $7 \%$ upon annealing at $500^{\circ} \mathrm{C}$ and around $10 \%$ upon annealing at $750^{\circ} \mathrm{C}$. Refractive indices increase with temperature: around $0.9 \%$ for $n_{M}$ and $n_{M}$ $x$ samples annealed at $500^{\circ} \mathrm{C}$ and $5 \%$ after treatment at $750^{\circ} \mathrm{C}$. For the rest of the mixture layers the increase is around a half value of the samples with high content of $\mathrm{Nb}_{2} \mathrm{O}_{5}$. This behaviour of indices and thicknesses indicates that density of the layers increases with annealing.

Dispersion curves of $\mathrm{AD}$ mixtures follow the theoretical LL dispersion curves very well (figure 2). The highest discrepancy from the curves is for $\mathrm{n}_{\mathrm{M}-\mathrm{x}}$ and $\mathrm{n}_{\mathrm{m}+\mathrm{x}}$ samples. The refractive indices at $570 \mathrm{~nm}$ as a function of $f_{v}\left(\mathrm{SiO}_{2}\right)$ are shown in figure 10, together with the theoretical values calculated from LL and LIN models. BG and MG models show nearly the 
same values as LIN model. Due to the lack of experimental data for $750^{\circ} \mathrm{C}$ annealed $\mathrm{Nb}_{2} \mathrm{O}_{5}$, the approximate value 2.41 reported in the literature [29], was taken for the simulations. It is clear that refractive indices of the samples follow LL and not LIN model, confirming appropriateness of application of LL model in optical characterisation. This is valid for both, $\mathrm{AD}$ and annealed samples, that is in contradiction with the expectations that after thermal treatment mixtures should separate into phases and should be best described by BG EMT ( similar to LIN).

FTIR spectra of AD samples (figure 3) show increase in intensity of bands at $1080 \mathrm{~cm}^{-}$ ${ }^{1}$ and $804 \mathrm{~cm}^{-1}$ with increased content of $\mathrm{SiO}_{2}$. The band assigned to $\mathrm{Si}-\mathrm{O}-\mathrm{Nb}$ bonds (around 920-930 $\mathrm{cm}^{-1}$ ) is especially pronounced for $\mathrm{n}_{\mathrm{m}}$ and $\mathrm{n}_{\mathrm{m}+\mathrm{x}}$ samples. Existence of this band suggests that $\mathrm{SiO}_{2}$ and $\mathrm{Nb}_{2} \mathrm{O}_{5}$ are mixed at atomic level having no significant separation of phases. The change of intensity of these peaks with temperature indicates breaking of Si-O$\mathrm{Nb}$ bonds followed by creation of $\mathrm{Si}-\mathrm{O}-\mathrm{Si}$ bonds (increase of band at $1080 \mathrm{~cm}^{-1}$ ). Thus, separation of phases occurs during temperature treatment. However, these bands remain visible even after annealing at $750^{\circ} \mathrm{C}$ (figure 3 , sample $\mathrm{n}_{\mathrm{m}}$ ) suggesting that the process is not completed. The increase of $\mathrm{Si}-\mathrm{O}-\mathrm{Si}$ band in $\mathrm{Nb}_{2} \mathrm{O}_{5}$ sample is attributed to the growth of native $\mathrm{SiO}_{2}$ layer at interface with $\mathrm{Si}$ substrate due to annealing.

Water absorption bands show that all the $\mathrm{AD}$ samples have pores filled with water molecules or that water is adsorbed at the surface of the coating (figure 4). In FTIR spectra measured three days upon annealing at $500^{\circ} \mathrm{C}$ (no change in spectra has been noticed after three days) these bands are significantly reduced or even absent. Upon annealing at $750^{\circ} \mathrm{C}$ none of the samples shows water absorption. Reduction of thickness found by optical characterisation can be related to the reduction of pore concentration in the layer. Indeed, area under water absorption peak is correlated with shrinking of the thickness. However, the samples after thermal treatment at $500^{\circ} \mathrm{C}$ already do not have water absorption bands, but their thickness reduces in even higher percent when annealed at $750^{\circ} \mathrm{C}$. This effect cannot be attributed only to restructuring due to crystallisation because it is evidenced also for samples that did not crystallize. So, although there is no water absorption in the layer (i.e. open voids that can be filled with water molecules), there are still remained closed pores, and thickness can be further reduced with annealing.

XRD of the samples annealed at $500^{\circ} \mathrm{C}$ show no crystallization. The first crystallisation in the samples appears between $500^{\circ} \mathrm{C}$ and $750^{\circ} \mathrm{C}$ and only for samples with highest content of $\mathrm{Nb}_{2} \mathrm{O}_{5}\left(\mathrm{n}_{\mathrm{M}-\mathrm{x}}, \mathrm{n}_{\mathrm{M}}\right.$ and $\left.\mathrm{Nb}_{2} \mathrm{O}_{5}\right)$ (figure 5). The peaks found for $\mathrm{n}_{\mathrm{M}-\mathrm{x}}$ and $\mathrm{n}_{\mathrm{M}}$ correspond to hexagonal crystal structure, while in the case of $\mathrm{Nb}_{2} \mathrm{O}_{5}$ sample there is clear splitting of peaks close to $28.5^{\circ}$ and $36.7^{\circ}$, that is characteristic for orthorhombic structure. 
The diffractograms of all the other samples present only halo from the Suprasil substrate and no diffraction pattern is distinguishable. The lack of defined XRD peaks indicates that $\mathrm{Nb}_{2} \mathrm{O}_{5}$ species are well dispersed in silica (and oppositely) as crystallites are smaller than 2-3 nm (detection limit), or they are present as an amorphous phase.

RMS roughness obtained from XRD analysis (table 3) does not present increase of roughness upon annealing for the mixture samples that have crystallized $\left(\mathrm{n}_{M}, \mathrm{n}_{M-\mathrm{x}}\right)$. It indicates that no big grains are formed on the surface. On the contrary, RMS roughness shows smoothening of the surface for these samples. It must be noticed that it is not expected that the method is precise enough for this level of roughness, but the trend should be correct. For the same samples also density increases after annealing. That is in accordance with decreasing of thickness and lower water absorption found from optical characterisation and FTIR measurements. However, for the $\mathrm{Nb}_{2} \mathrm{O}_{5}$ sample RMS has significantly increased. This is related to the formation of big crystalline grains that highly contribute to the scattering of this sample.

Indeed, RMS values obtained from AFM measurements (table 3) confirm big grains at the surface of $\mathrm{Nb}_{2} \mathrm{O}_{5}$ sample (figure 6). The difference in RMS values of the two techniques for this sample can originate from the scale on which measurements have been performed. RMS values obtained from XRD and AFM measurements are qualitatively in accordance with the level of scattering found in the annealed mixture samples.

SAED patterns of $\mathrm{AD} \mathrm{Nb}_{2} \mathrm{O}_{5}$ (not shown) and $\mathrm{n}_{\mathrm{M}}$ samples (figure 8) confirm the amorphous structure found by XRD. The spots originate from reflections on Si crystalline structure of the substrate, while rings indicate amorphous structure of the layer. In HRTEM image it is possible to see 4-7 $\mathrm{nm}$ of $\mathrm{SiO}_{2}$ layer at the interface between the substrate and the coating, that is previously mentioned native film growing on Si exposed to the atmosphere. It is possible to see that the structure of the layers is porous, that is again in accordance with FTIR results. Pores are elongated going from the bottom to the top of the coating. In the beginning of growth there are no pores. The thickness of the coatings for $\mathrm{Nb}_{2} \mathrm{O}_{5}$ and $\mathrm{n}_{\mathrm{M}} \mathrm{AD}$ samples found by TEM are $450 \pm 20 \mathrm{~nm}$ that corresponds to the result from optical characterisation.

Diffractogram of the $n_{M}$ sample annealed at $750^{\circ} \mathrm{C}$ (figure 9) shows that the layer is well crystallized, as expected from XRD results. There is no preferable orientation of the structure in relation to the Si substrate (no overlap with Si substrate reflections). Z-contrast image demonstrates that the sample is multilayered film of total thickness $400 \pm 20 \mathrm{~nm}$, again in agreement with thickness from optical characterisation. The native $\mathrm{SiO}_{2}$ layer has approximately doubled its thickness with annealing. This is related to the development of 
FTIR Si-O-Si band in $\mathrm{Nb}_{2} \mathrm{O}_{5}$ sample. Z-contrast image indicates that 10-30 nm thick layers consist of element with high atomic number $(\mathrm{Nb})$. They are separated by layers of 1-3 $\mathrm{nm}$ of light element $(\mathrm{Si})$. Although the layered structure demonstrates separation of the mixture into phases, HRTEM images show that they are not well defined. This can be related to the results of FTIR that $\mathrm{Si}-\mathrm{O}-\mathrm{Nb}$ bands of some samples remain detectable even after annealing at $750^{\circ} \mathrm{C}$, indicating that the process of separation in phases is not completed. Also, this can be correlated with optical characterisation results showing that refractive indices of the mixtures are best described by LL EMT even upon annealing. Indeed, the limits of phase size for BG and MG theory to become effective is $3-30 \mathrm{~nm}$ [20] (visible to mid-infrared wavelengths). The uncompleted separation of phases into layers of 1-3 nm is obviously under this limit. Therefore, LL model should be implemented into the design software to simplify linking design and volume fraction values that should be controlled in the deposition process to obtain desired refractive index profile.

The multilayer structure of the annealed $n_{M}$ coating is unexpected. However, it can be related to the previous study [22] presenting periodical regions of higher and lower content of $\mathrm{SiO}_{2}$ in the mixture coating deposited as a layer of constant refractive index. This periodicity has been related to the rotation of the sample placed at calotte and lateral positions of evaporation material crucibles indicating that the mixture of materials in the vapour is not uniform in the chamber. The concentration of the corresponding material in the vapour is higher above the crucible. It is possible that during annealing, due to crystallisation, the regions poor in one material become even more depleted resulting in layered structure more pronounced than in $\mathrm{AD}$ coating.

\section{Conclusions}

Results of optical characterisation of $\mathrm{Nb}_{2} \mathrm{O}_{5}-\mathrm{SiO}_{2}$ mixture samples show that refractive indices of both, as deposited and annealed samples, follow LL EMT. Structural analysis of as deposited samples (FTIR, XRD diffractograms, TEM) shows that the materials are well mixed, at atomic level ( $\mathrm{Si}-\mathrm{O}-\mathrm{Nb}$ bonds). There is no separation into phases for these samples, which is condition for validity of LL EMT. The materials in the mixture layers show phase separation and crystallisation after annealing (FTIR, XRD, TEM, AFM, scattering). The process of separation remains uncompleted and size of phase grains insufficient after annealing at $750^{\circ} \mathrm{C}$ for BG or LIN EMT to become effective for electron beam deposited $\mathrm{Nb}_{2} \mathrm{O}_{5}-\mathrm{SiO}_{2}$ mixtures (FTIR, HRTEM). Thus, LL EMT has been shown as the most appropriate model for $\mathrm{Nb}_{2} \mathrm{O}_{5}-\mathrm{SiO}_{2}$ mixtures both, by optical characterisation and by relating optical parameters of the mixtures to the structure of the mixtures. LL EMT should be taken 
into consideration when developing algorithm for design of gradient index coatings to simplify the transition from design to the corresponding deposition process.

\section{Acknowledgements}

Special thanks to Olaf Stenzel for support and advices. The authors thank Heidi Haase for technical assistance and Sabine Grözinger for TEM sample preparation. Vesna Janicki wishes to thank the Fraunhofer Society in Germany for a Fraunhofer Fellowship at IOF in Jena.

\section{References}

[1] W. H. Southwell, J. Opt. Soc. Am. A 5 (1988) 1558-1564.

[2] T. D. Rahmlow, Jr., J. E. Lazo-Wasem, Proc. SPIE 3133 (1997) 25-35.

[3] P. G. Verly, J. A. Dobrowolski, Appl. Opt. 29 (1990) 3672-3684.

[4] D. Rats, D. Poitras, J. M. Soro, L. Martinu, J. von Stebut, Surf. Coat. Tech. 111 (1999) 220-228.

[5] M.-A. Raymond, S. Larouche, O. Zabeida, L. Martinu, J. E. Klemberg-Sapieha, Proc. $44^{\text {th }}$ Ann. Tech. Conf. Soc. of Vacuum Coaters, (2001) pp. 301-305.

[6] R. Vernhes, O. Zabeida, J. E. Klemberg-Sapieha, L. Martinu, Appl. Opt. 43 (2004) $97-$ 103.

[7] D. Ristau, H. Schink, F. Mittendorf, J. Akhtar, J. Ebert, H. Welling, NIST Spec. Publ. 775 (1988) 414-426.

[8] D. A. Bruggeman, Ann. Phys. 24 (1935) 636-679.

[9] L. Lorenz, Ann. Phys. 11 (1880) 70-103.

[10] J. C. Maxwell Garnett, Philos. Trans. R. Soc. A 203 (1904) 385-420.

[11] A. V. Tikhonravov, M. K. Trubetskov, T. V. Amotchkina, M. A. Kokarev, N. Kaiser, O. Stenzel, S. Wilbrandt, D. Gäbler, Appl. Opt. 45 (2006) 1515-1532.

[12] V. Janicki, S. Wilbrandt, O. Stenzel, D. Gäbler, N. Kaiser, A. Tikhonravov, M. Trubetskov, T. Amotchkina, J. Opt. A: Pure Appl. Opt. 7 (2005) L9-L12.

[13] S. W. Wang, X. X. Huang, J. K. Guo, B. S. Li, Mater. Lett. 28 (1996) 43-46.

[14] N. Özer, M. D. Rubin, C. M. Lampert, Sol. Energ. Mat. Sol. C. 40 (1996) 285-296.

[15] A. Pawlicka, M. Atik, M. A. Aegerter, Thin Solid Films 301 (1997) 236-241.

[16] M. Paulis, M. Martín, D. B. Soria, A. Díaz, J. A. Odriozola, M. Montes, Appl. Catal. A 180 (1999) 411-420.

[17] Powder Diffraction File, Joint Committee on Powder Diffraction Standards, International Centre for Diffraction Data, 1601 Park Lane, Swarthmore, PA 19081, USA. 
[18] S. Larouche, H. Szymanowski, J. E. Klemberg-Sapieha, L. Martinu, J. Vac. Sci. Technol. A 22(4) (2004) 1200-1207.

[19]. M. S. P. Francisco, Y. Gushikem, J. Mater. Chem. 12 (2002) 2552-2558.

[20] G. A. Niklasson, C. G. Granqvist, O. Hunderi, Appl. Opt. 20 (1981) 26-30.

[21] D. E. Aspnes, Thin Solid Films 89 (1982) 249-262.

[22] R. Leitl, O. Stenzel, S. Wilbrandt, D. Gäbler, V. Janicki, N. Kaiser, Thin Solid Films 497 (2006) 135-141.

[23] V. Janicki, D. Gäbler, S. Wilbrandt, R. Leitel, O. Stenzel, N. Kaiser, M. Lappshies, B. Görtz, D. Ristau, C. Rickers, M. Vergöhl, Appl. Opt. 45 (2006) 7851-7857.

[24] S. Bosch, J. Ferré-Borrull, J. Sancho-Parramon, Solid State Electron. 45 (2001) 703-709.

[25] J. Tauc, R. Grigorovici, A. Vancu, Phys. Stat. Sol. 15 (1966) 627-637.

[26] G. E. Jellison Jr., F. A. Modine, Appl. Phys. Lett. 69 (1966) 371-373.

[27] E. B. Pereira, M. M. Pereira, Y. L. Lam, C. A. C. Perez, M. Schmal, Appl. Catal. A 197 (2000) 99-106.

[28] S. Laux, W. Richter, Appl. Opt. 35 (1996) 97-101.

[29] J.-P. Masse, H. Szymanowski, O. Zabeida, A. Amassian, J. E. Klemberg-Sapieha, L. Martinu, Thin Solid Films 515 (2006) 1674-1682. 
Table 1. Set rates of deposition $\left(r_{s e t}\right), f_{v}\left(\mathrm{SiO}_{2}\right)$ and thickness $d$ of the mixture layers calculated from recorded rates of deposition

\begin{tabular}{cccc}
\hline Sample & $\begin{array}{c}r_{\text {set }}\left(\mathrm{Nb}_{2} \mathrm{O}_{5}\right) / r_{\text {set }}\left(\mathrm{SiO}_{2}\right) \\
(\mathrm{nm} / \mathrm{s})\end{array}$ & $\begin{array}{c}f_{v}\left(\mathrm{SiO}_{2}\right) \text { from } r(t) \\
(\mathrm{nm})\end{array}$ \\
\hline $\mathrm{n}_{\mathrm{M}}$ & $1.2 / 0.3$ & 0.197 & 446.91 \\
$\mathrm{n}_{\mathrm{M}-\mathrm{x}}$ & $0.95 / \mathbf{0 . 5 5}$ & 0.357 & 439.63 \\
$\mathrm{n}_{\mathrm{MED}}$ & $0.75 / 0.75$ & 0.486 & 439.76 \\
$\mathrm{n}_{\mathrm{m}+\mathrm{x}}$ & $0.55 / 0.95$ & 0.615 & 428.10 \\
$\mathrm{n}_{\mathrm{m}}$ & $0.3 / 1.2$ & 0.784 & 429.02 \\
\hline
\end{tabular}

Table 2. Results of optical characterisation of as deposited and annealed mixture samples

\begin{tabular}{|c|c|c|c|c|}
\hline & & $\begin{array}{c}n \text { at } \\
570 \mathrm{~nm}\end{array}$ & $\begin{array}{c}d \\
(\mathrm{~nm})\end{array}$ & model \\
\hline \multirow[t]{2}{*}{$\mathrm{Nb}_{2} \mathrm{O}_{5}$} & $\mathrm{AD}$ & 2.284 & 450.3 & $\mathrm{TL}$ \\
\hline & $500^{\circ} \mathrm{C}$ & 2.313 & 436.7 & $\mathrm{TL}$ \\
\hline \multirow[t]{3}{*}{$\mathrm{n}_{\mathrm{M}}$} & $\mathrm{AD}$ & 2.086 & 449.6 & TL \\
\hline & $500^{\circ} \mathrm{C}$ & 2.104 & 433.5 & TL \\
\hline & $750^{\circ} \mathrm{C}$ & 2.186 & 404.2 & $\mathrm{C}$ \\
\hline \multirow[t]{3}{*}{$\mathrm{n}_{\mathrm{M}-\mathrm{x}}$} & $\mathrm{AD}$ & 1.903 & 506.8 & $\mathrm{C}$ \\
\hline & $500^{\circ} \mathrm{C}$ & 1.920 & 481.2 & $\mathrm{C}$ \\
\hline & $750^{\circ} \mathrm{C}$ & 1.993 & 442.9 & $\mathrm{C}$ \\
\hline \multirow[t]{3}{*}{$\mathrm{n}_{\mathrm{MED}}$} & $\mathrm{AD}$ & 1.839 & 464.0 & $\mathrm{C}$ \\
\hline & $500^{\circ} \mathrm{C}$ & 1.840 & 441.1 & $\mathrm{C}$ \\
\hline & $750^{\circ} \mathrm{C}$ & 1.892 & 415.3 & $\mathrm{C}$ \\
\hline \multirow[t]{3}{*}{$\mathrm{n}_{\mathrm{m}+\mathrm{x}}$} & $\mathrm{AD}$ & 1.707 & 500.6 & $\mathrm{C}$ \\
\hline & $500^{\circ} \mathrm{C}$ & 1.714 & 473.9 & $\mathrm{C}$ \\
\hline & $750^{\circ} \mathrm{C}$ & 1.746 & 430.0 & $\mathrm{C}$ \\
\hline \multirow[t]{3}{*}{$\mathrm{n}_{\mathrm{m}}$} & $\mathrm{AD}$ & 1.600 & 471.7 & $\mathrm{C}$ \\
\hline & $500^{\circ} \mathrm{C}$ & 1.597 & 453.8 & $\mathrm{C}$ \\
\hline & $750^{\circ} \mathrm{C}$ & 1.599 & 421.6 & $\mathrm{C}$ \\
\hline $\mathrm{SiO}_{2}$ & $\mathrm{AD}$ & 1.467 & 507.3 & $\mathrm{C}$ \\
\hline
\end{tabular}


Table 3. Comparison of roughness values obtained from AFM and XRD, density $(\rho)$ of the layers obtained from XRD analysis

\begin{tabular}{ccccccc}
\hline & \multicolumn{2}{c}{ roughness AFM $(\mathrm{nm})$} & \multicolumn{2}{c}{ roughness XRD $(\mathrm{nm})$} & \multicolumn{2}{c}{$\rho$ XRD $\left(\mathrm{g} / \mathrm{cm}^{3}\right)$} \\
Sample & $\mathrm{AD}$ & $750^{\circ} \mathrm{C}$ & $\mathrm{AD}$ & $750^{\circ} \mathrm{C}$ & $\mathrm{AD}$ & $750^{\circ} \mathrm{C}$ \\
\hline $\mathrm{Nb}_{2} \mathrm{O}_{5}$ & 0.94 & 11.96 & 1.7 & 3.3 & 4.5 & 4.5 \\
$\mathrm{n}_{\mathrm{M}}$ & 1.03 & 1.24 & 1.8 & 1.6 & 4.3 & 4.4 \\
$\mathrm{n}_{\mathrm{M}-\mathrm{x}}$ & - & - & 2.0 & 1.3 & 3.65 & 4.0 \\
$\mathrm{n}_{\mathrm{MED}}$ & 1.05 & 1.22 & - & - & - & - \\
$\mathrm{n}_{\mathrm{m}+\mathrm{x}}$ & - & 1.44 & - & - & - & - \\
$\mathrm{n}_{\mathrm{m}}$ & 1.36 & 1.47 & - & - & - & - \\
$\mathrm{SiO}_{2}$ & 1.82 & - & - & - & - & - \\
\hline
\end{tabular}




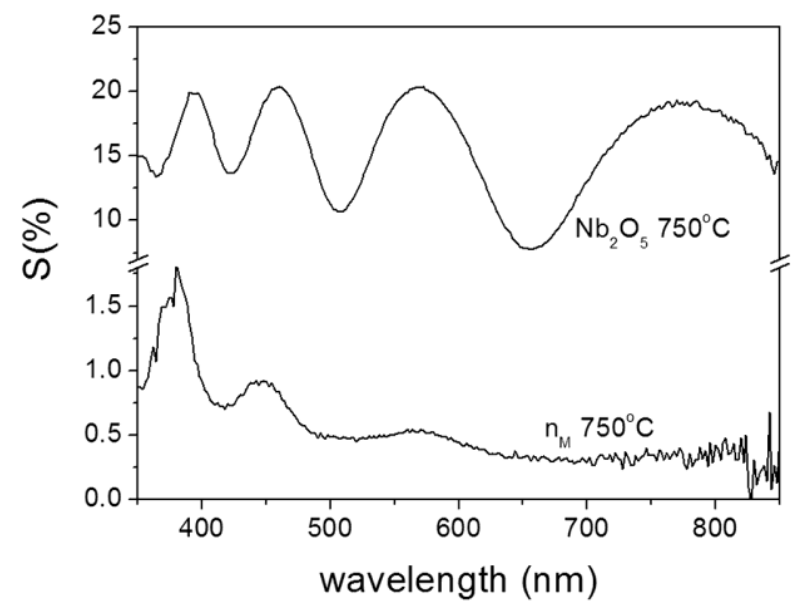

Figure 1. Scattering of the annealed high content $\mathrm{Nb}_{2} \mathrm{O}_{5}$ samples prepared on Suprasil substrate.
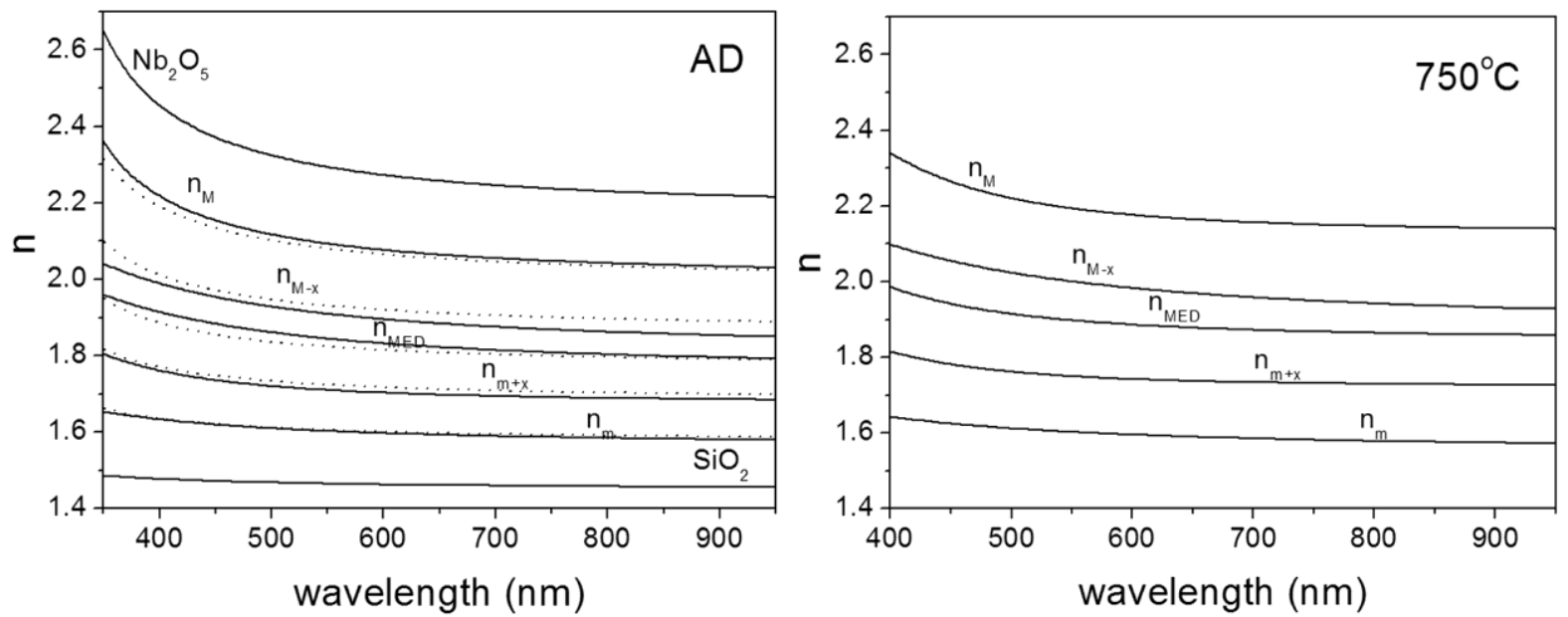

Figure 2. Refractive index dispersions of the mixture samples, as deposited (AD) and annealed at $750^{\circ} \mathrm{C}$. Theoretical LL dispersion curves for corresponding AD samples are presented with dots.
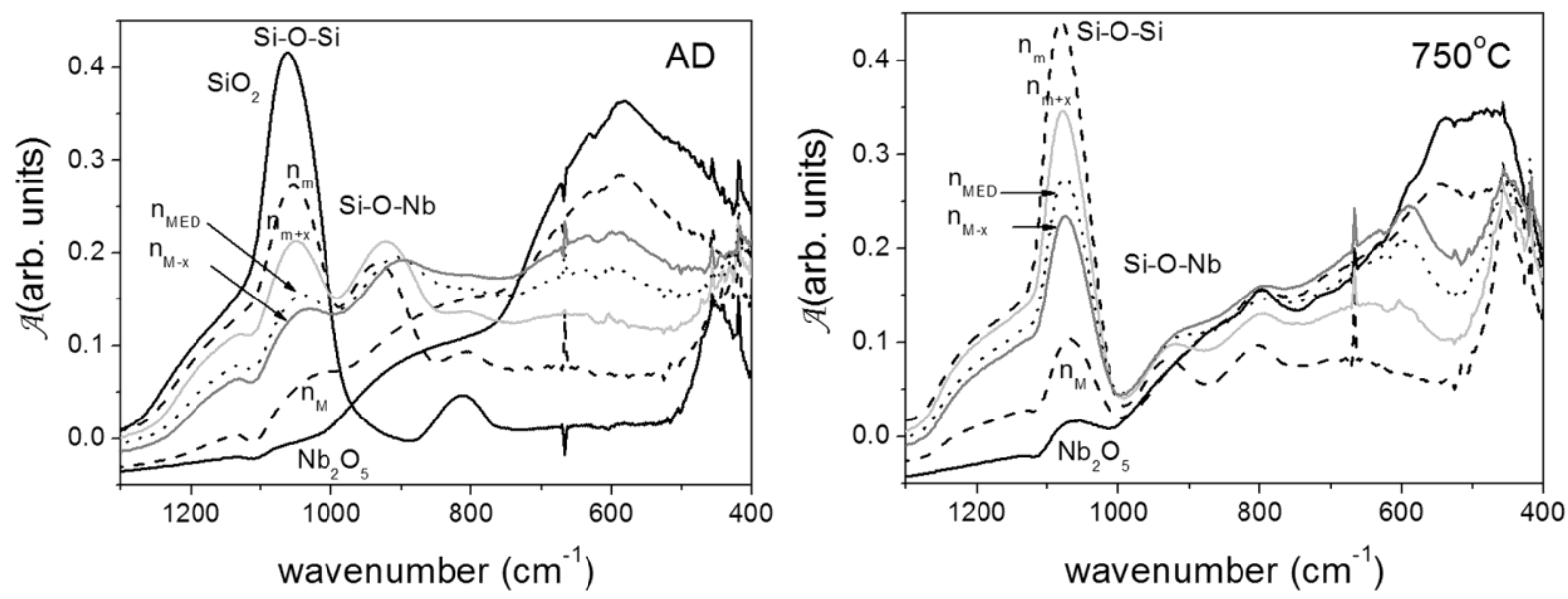

Figure 3. FTIR spectra of $A D$ and annealed mixture samples deposited on silicon wafer chunks. 


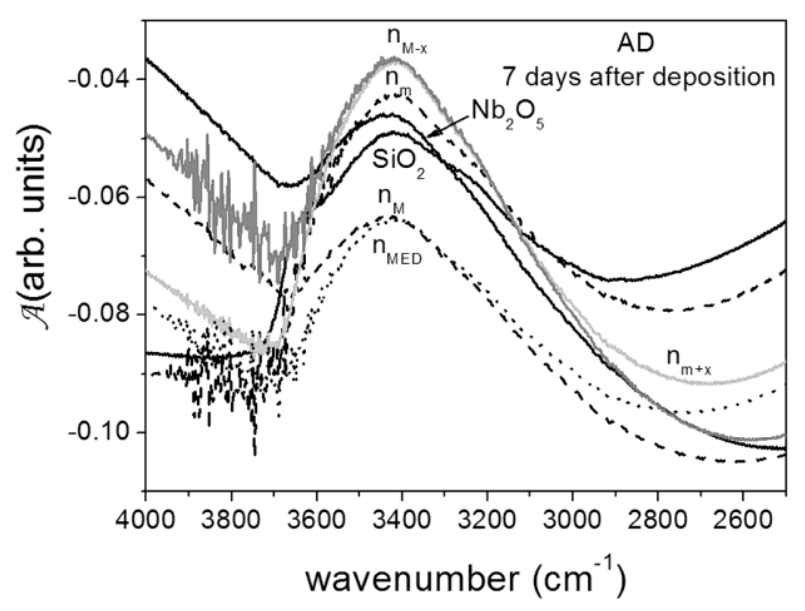

Figure 4. Water absorption band of the mixture samples deposited on silicon wafer chunks.

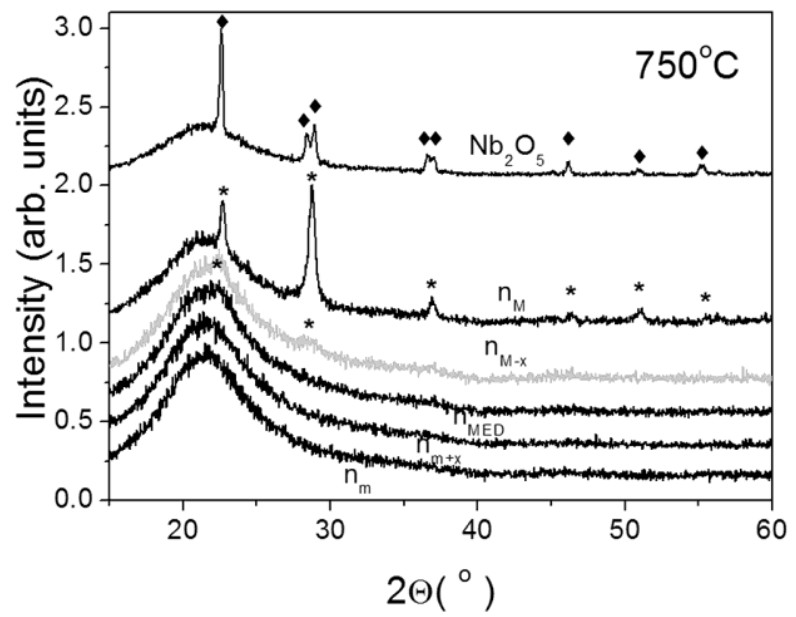

Figure 5. LAXD spectra of samples prepared on Suprasil substrates annealed at $750^{\circ} \mathrm{C}$. The crystallization was found for the three samples with highest content of $\mathrm{Nb}_{2} \mathrm{O}_{5}$ annealed at $750^{\circ} \mathrm{C}$. Peaks characteristic for hexagonal structure are denoted with $*$ and those characteristic for orthorhombic with $\bullet$.
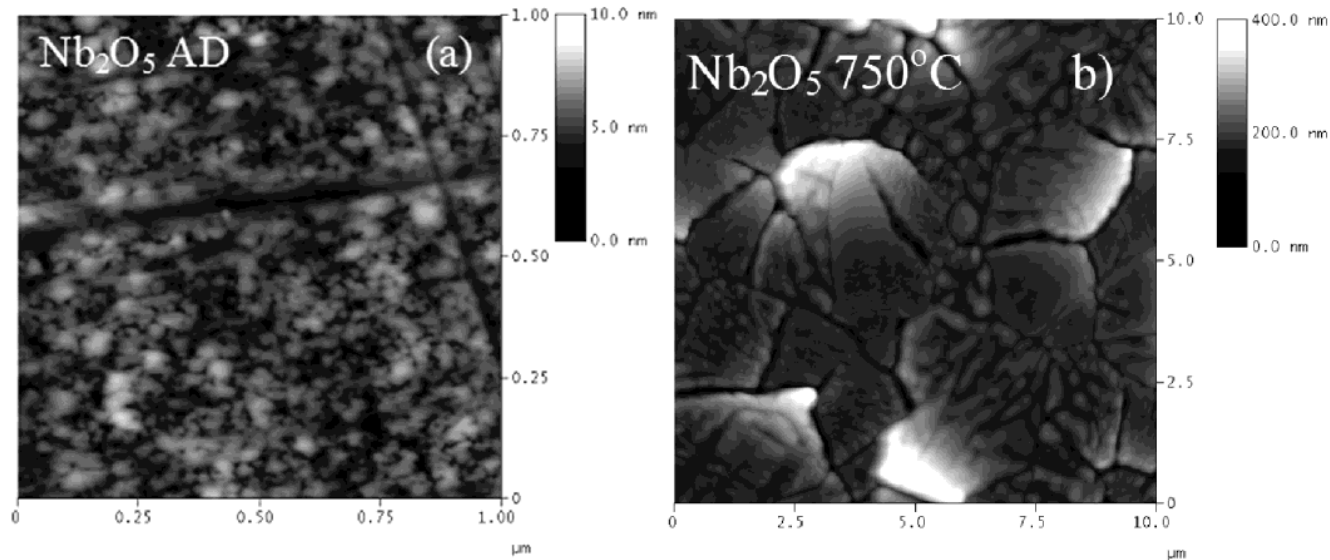

Figure 6. AFM pictures of $\mathrm{Nb}_{2} \mathrm{O}_{5}$ sample prepared on Suprasil substrate $\mathrm{AD}$ (a) and annealed at $750^{\circ} \mathrm{C}(\mathrm{b})$. 


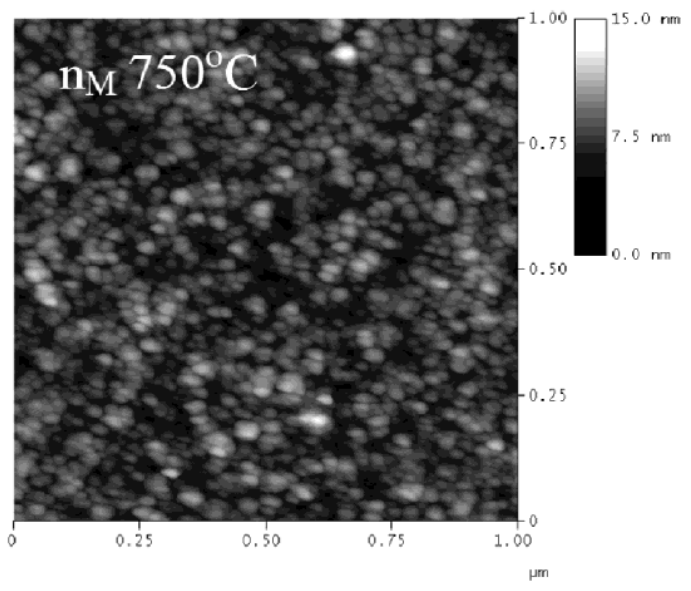

Figure 7. AFM picture of $n_{M}$ sample prepared on Suprasil substrate annealed at $750^{\circ} \mathrm{C}$.
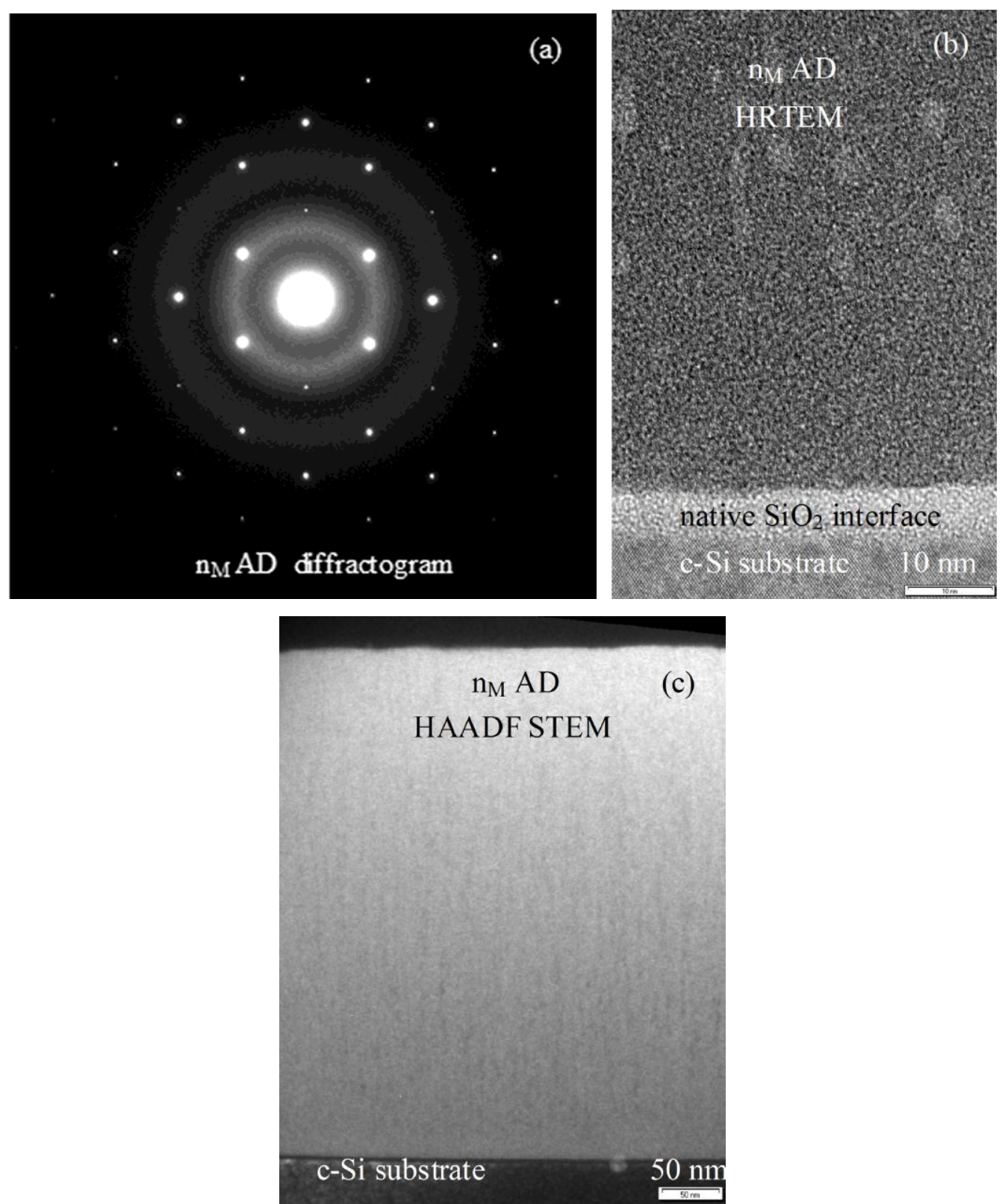

Figure 8. SAED (a), HRTEM (b) and HAADF STEM (c) images of AD $\mathrm{n}_{M}$ sample deposited on silicon wafer chunk. 

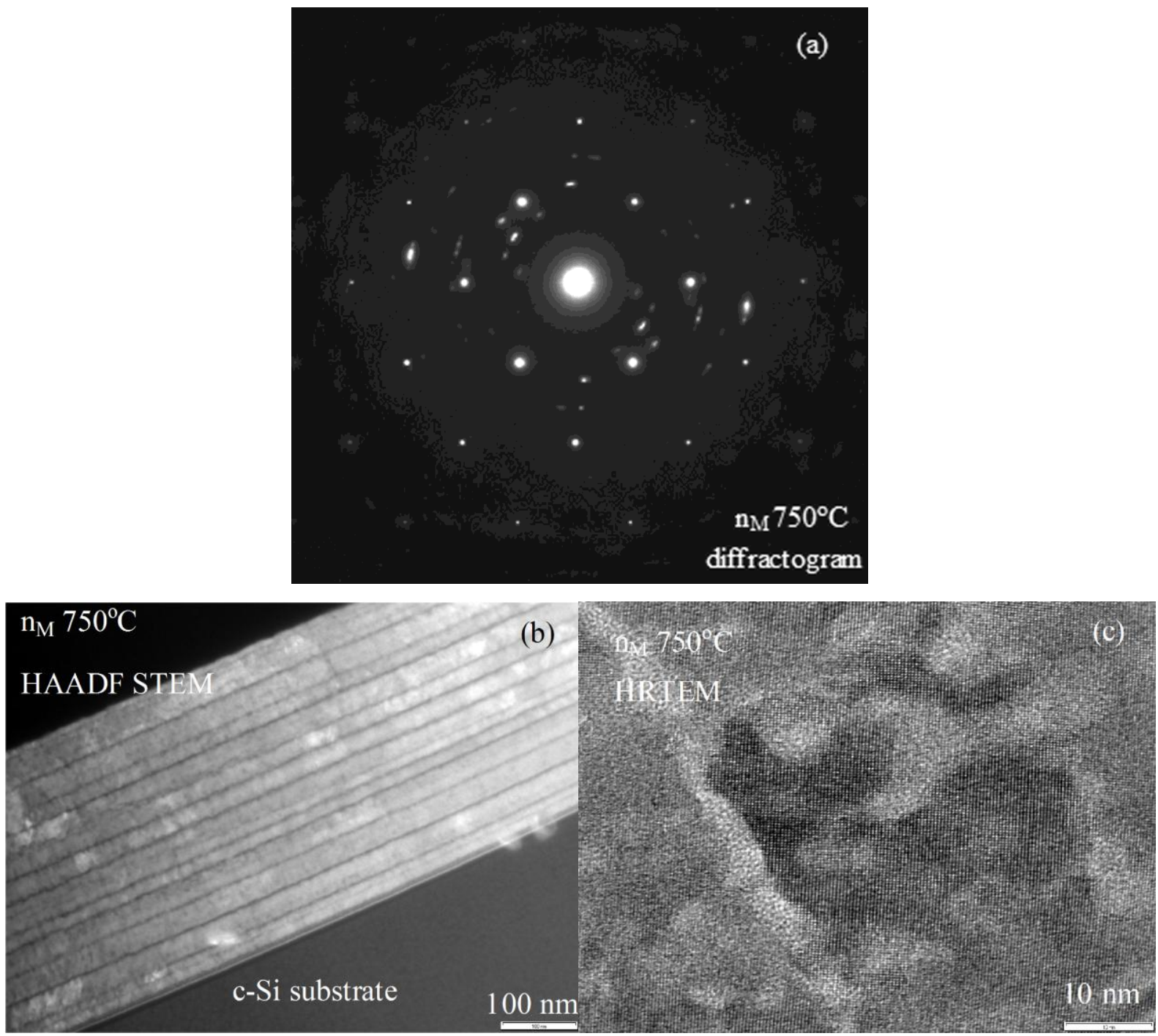

Figure 9. SAED (a), HAADF STEM (b) and HRTEM (c) images of $n_{M}$ sample deposited on silicon wafer chunk annealed at $750^{\circ} \mathrm{C}$.
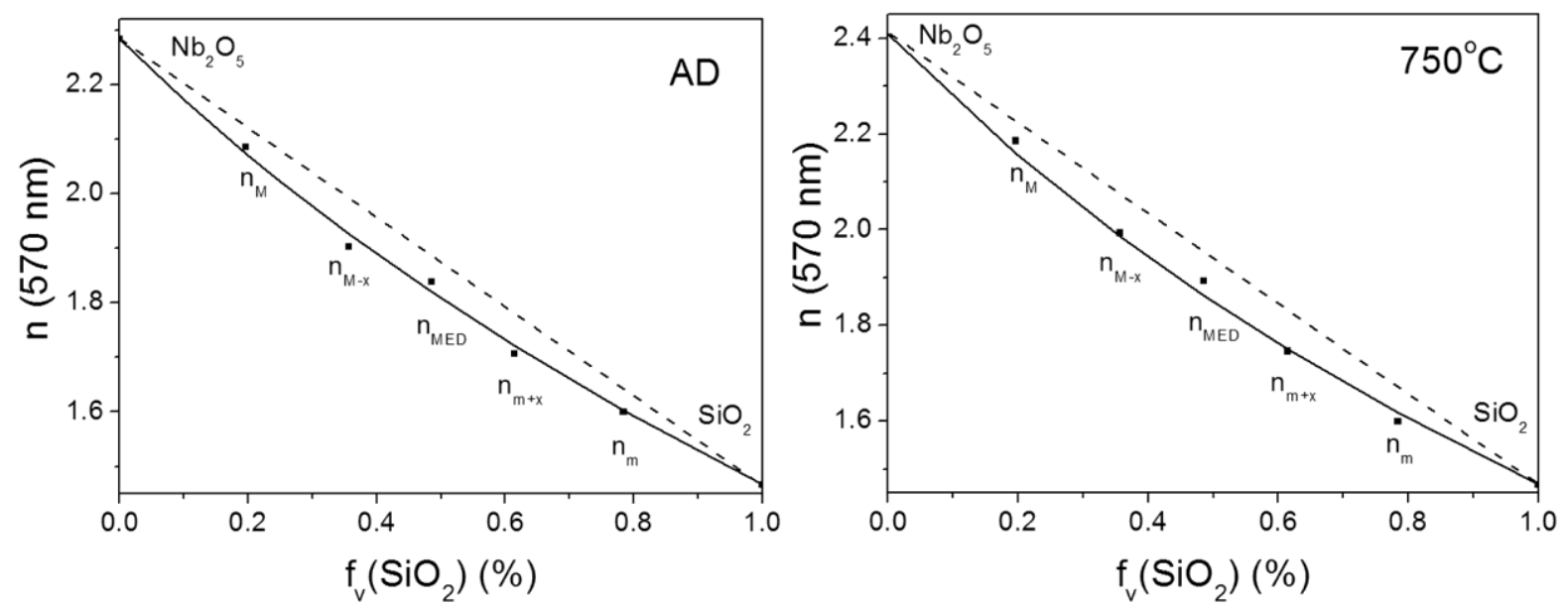

Figure 10. Refractive indices at wavelength $570 \mathrm{~nm}$ of the mixture samples (rectangles), together with theoretical curves for LL (solid line) and LIN model (dashes). 